\title{
Isokinetic Peak Torque Rotations in Dominant Arms Between Powerlifters and Healthy Controls.
}

Erick G. P. de Lucena*, Guilherme H. J. Silva, João P. Silvério, Cassiano A. Massafera, Adonias O. F. de Souza, Luis F. M. Teixeira, Marco C. Uchida.

\begin{abstract}
Powerlifting is a sport based in maximal strength in three exercises: i) squat, ii) bench press and iii) deadlift. Specifically, on squat and the bench press, the shoulder joint stay at some positions and ranges of motion with overload. The aim of this study was to compare peak torque (PT; Nm) in dominant arms (D) between powerlifters and physical active people for shoulder external (ER) and internal rotation (IR). The participants were male, two groups, 14 recreationally powerlifters $(P L)$ and 14 recreationally physical active people $(A P)$. The PT for ER and IR of shoulder joint were assessed by Biodex isokinetic dynamometer, $60 \%$ s and $180 \%$ s concentric mode was adopted for velocity degree. The $\mathrm{D}$ shoulder ER and IR between PL and AP were compared with unpaired student's t-test. There was no significant difference between PL and AP at $60 \%$ for ER $(p=0.09)$ and IR $(p=0.05)$; and $180 \%$ for $E R(p=0.12)$ and IR $(p=0.09)$. Despite Powerlifting being a strength sport modality, there are not significant differences between the peak torque in recreationally powerlifters and physical active people in ER and IR in two different velocities.
\end{abstract}

Key words: Shoulder Joint, Isokinetic Dynanometer, Peak Torque.

\section{Introduction}

Powerlifting is a sport based in maximal strength in three exercises: i) squat, ii) bench press and iii) deadlift ${ }^{1}$. Specifically, on squat and the bench press, the shoulder joint stay at some positions and ranges of motion with overload, which may result in specific adaptations ${ }^{2}$, powerlifters probably have more strength than active people. The isokinetic dynamometer allows quantify the muscle performance (i.e. work; peak torque) in some velocity degrees. The aim of this study was to compare peak torque (PT; Nm) in dominant arms (D) between powerlifters and physical active people for shoulder external (ER) and internal rotation (IR) .

\section{Results and Discussion}

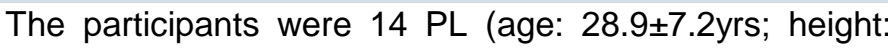
175.1 $\pm 6.7 \mathrm{~cm}$; weight: $83.9 \pm 13.8 \mathrm{~kg}$ ) and $14 \mathrm{AP}$ (age: 26.6 $\pm 6.8 \mathrm{yrs}$; height: $178.2 \pm 5.2 \mathrm{~cm}$; weight: $81.5 \pm 13.0 \mathrm{~kg}$ ). The tests were conducted on $D$ upper limb, for shoulder ER and shoulder IR by Biodex isokinetic dynamometer. The participants were in a seated position, $45^{\circ}$ shoulder abduction. PT were registered at $60 \%$ s and $180 \% \mathrm{~s}$ concentric mode, with 5 repetitions at each velocity degree, 1-min was adopted for rest interval between each series/velocity. The $D$ shoulder ER and IR between PL and AP were compared with unpaired student's t-test, the level of significance was $p<0.05$.

There was no significant difference between $\mathrm{PL}$ and $\mathrm{AP}$ at $60 \%$ for ER (a. $p=0.09 ; P L=38.9 \pm 10.1 \mathrm{~N} \mathrm{~m}$, $A P=33.1 \pm 7.7 \mathrm{Nm}$ ) and IR (b. $\mathrm{P}=0.05 ; \mathrm{PL}=60.6 \pm 16.6 \mathrm{Nm}$, $A P=49.1 \pm 13.1 \mathrm{Nm}$ ), at $180 \%$ for $E R$ (c. $p=0.12$; $P L=39.5 \pm 9.8 \mathrm{Nm}, A P=34.4 \pm 6.9 \mathrm{Nm}$ ) and $I R$ (d. $p=0.09$; $P L=59.7 \pm 17 \mathrm{Nm}, A P=50.1 \pm 11.9 \mathrm{Nm}$. See Figure 1 .

No significant differences between groups could be explained by specific movements demands of shoulder joint in Powerlifting. Shoulder rotations movements are not common on Powerlifting exercises ${ }^{1}$. Meanwhile, exercises for shoulder rotators muscles must be included on training plan for strengthening ${ }^{3}$.
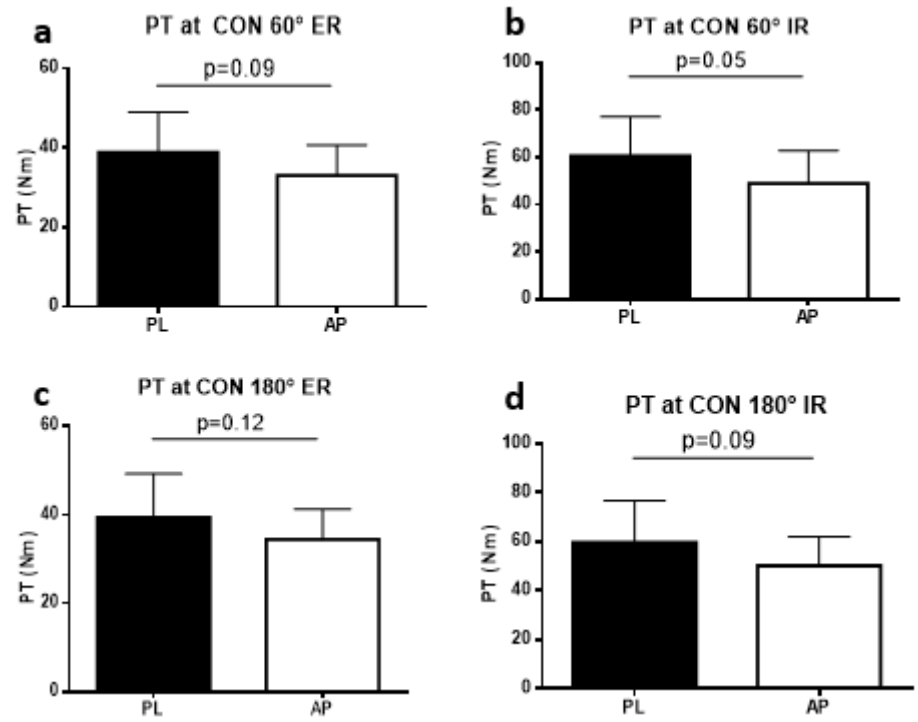

Figure 1. Dominant shoulder joint Peak Torque $(\mathrm{Nm})$ of Powerlifters $(\mathrm{PL})$ and Active People (AP). CON $60^{\circ}=$ concentric mode at $60^{\circ} / \mathrm{s}$. CON $180^{\circ}=$ concentric mode at $180^{\circ} / \mathrm{s}$.

\section{Conclusions}

Despite Powerlifting being a strength sport modality, there are not significant differences between the peak torque in recreationally powerlifters and physical active people in ER and IR for two different velocities.

\section{Acknowledgement}

Thanks to the National Scientific and Technological Development (CNPq) \#118276/2018-2 and São Paulo Research Foundation (FAPESP) \#2018/11513-2.

\footnotetext{
1 FERLAND, Pierre-Marc; COMTOIS, Alain S. Classic Powerlifting Performance: A Systematic Review. Journal of Strength and Conditioning Research, 2019

2 BENGTSSON, Victor; BERGLUND, Lars; AASA, Ulrika. Narrative review of injuries in powerlifting with special reference to their association to the squat, bench press and deadlift. BMJ Open Sport \& Exercise Medicine, v. 4, n. 1, p. e000382, 2018.

${ }^{3}$ LUCENA, Erick G.P. et al. Comparison in Peak Torque Rotations Between Dominant and Non-Dominant Arms in Powerlifters. Medicine and Science in Sports and Exercise, v. 49. p. 31-31, 2019.
} 